This manuscript was accepted and published by Energy \& Fuels, a journal of the American Chemical Society.

Publication data of the final, corrected work:

Antal, M. J., Jr.; Várhegyi, G.: Impact of systematic errors on the determination of cellulose pyrolysis kinetics. Energy Fuels 1997, 11, 1309-1310. doi:

$\underline{10.1021 / \mathrm{ef} 970030 \mathrm{w}}$

\title{
Impact of Systematic Errors on the Determination of Cellulose Pyrolysis Kinetics
} Michael Jerry Antal, Jr.*

Hawaii Natural Energy Institute and the Department of Mechanical Engineering, University of Hawaii at Manoa, Honolulu, Hawaii 96822

\section{Gábor Várhegyi}

Research Laboratory for Inorganic Chemistry, Hungarian Academy of Sciences, Pf. 132, Budapest 1518, Hungary

It is difficult to imagine an experiment that is free from the intrusion of systematic errors. Consequently, successful experimentalists always concern themselves with the detection of such errors, and the quantification of their influence upon the results of an experimental campaign. In this paper we discuss the impacts of systematic errors in temperature measurement on the determination of cellulose pyrolysis kinetics by thermogravimetric analysis (TGA). We also offer insights into the importance of other systematic errors in studies of cellulose pyrolysis kinetics by Pyromat micropyrolysis, ${ }^{1}$ which may explain why kinetic parameters determined by the Pyromat do not agree with those deduced from TGA data. ${ }^{1}$

Figure 1 displays TG analyses of Avicel PH-105 cellulose in helium and argon at three different heating rates, together with simulated weight loss curves obtained from first order kinetic models. The helium experiments were conducted during two consecutive days; whereas the argon experiments span a ten year period. Two of the experimental curves were presented as Figure 1 in an earlier paper, ${ }^{2}$ and were a focus of attention in the recent work of Reynolds and Burnham. ${ }^{1}$ If we use non-linear least squares ${ }^{3,4}$ to determine the best fit values of the first order rate constants $\mathrm{E}$ and $\log \mathrm{A}$ for the $2{ }^{\circ} \mathrm{C} / \mathrm{min}$ data, we obtain the results listed in the "Variable E" section of Table 1. 

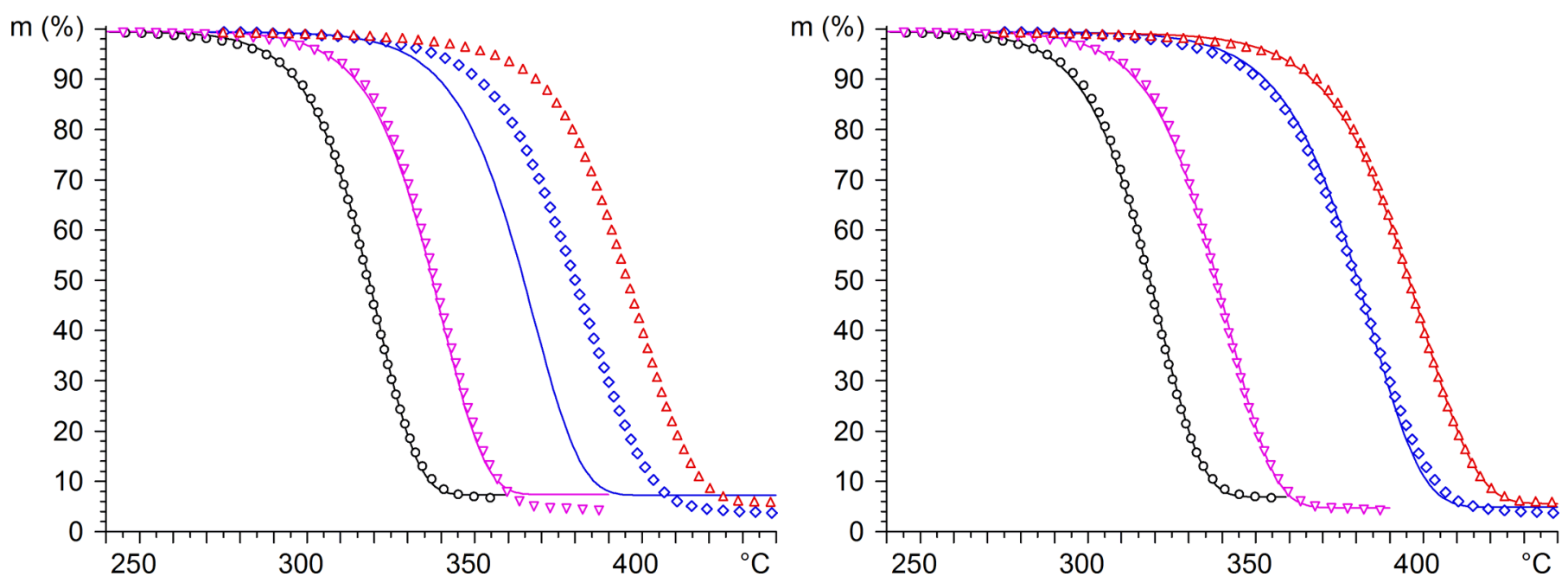

Figure 1. Kinetic evaluations of Avicel cellulose TG curves. Experiments from left to right: $2{ }^{\circ} \mathrm{C} / \mathrm{min}(3$ $\mathrm{mg})$ in $\mathrm{He}(0) ; 10^{\circ} \mathrm{C} / \mathrm{min}(3 \mathrm{mg})$ in $\mathrm{He}(\nabla), 81^{\circ} \mathrm{C} / \mathrm{min}(0.5 \mathrm{mg})$ in $\mathrm{Ar}(\diamond) ; 77^{\circ} \mathrm{C} / \mathrm{min}(0.5 \mathrm{mg})$ in $\operatorname{Ar}(\Delta)$. Panel A: simulated curves $\left(-,-,-\right.$ ) calculated from the least squares parameters of the $2{ }^{\circ} \mathrm{C} / \mathrm{min}$ experiment. Panel B: best fitting curves $(-,-,-,-$,$) with identical activation energies for all$ experiments.

Table 1: Kinetic evaluation of Avicel cellulose TG curves.

\begin{tabular}{|c|c|c|c|c|c|c|c|c|c|c|}
\hline \multirow[b]{2}{*}{$\begin{array}{c}\mathrm{dT} / \mathrm{dt} \\
\left({ }^{\circ} \mathrm{C} / \mathrm{min}\right)\end{array}$} & \multicolumn{5}{|c|}{$\begin{array}{l}\text { Independent evaluation } \\
\text { (variable E) }\end{array}$} & \multicolumn{5}{|c|}{$\begin{array}{l}\text { Simultaneous evaluation } \\
\text { (identical E) }\end{array}$} \\
\hline & $\begin{array}{c}\mathrm{E} \\
(\mathrm{kJ} / \mathrm{mol})\end{array}$ & $\begin{array}{c}\log \mathrm{A} \\
\left(\log \mathrm{S}^{-1}\right)\end{array}$ & $\mathrm{m}_{\mathrm{f}}$ & $\begin{array}{l}\text { fit } \\
(\%)\end{array}$ & $\begin{array}{l}\mathrm{k}_{350^{\circ} \mathrm{C}} \\
10^{-3} \mathrm{~s}^{-1}\end{array}$ & $\begin{array}{c}\mathrm{E} \\
(\mathrm{kJ} / \mathrm{mol})\end{array}$ & $\begin{array}{c}\log \mathrm{A} \\
\left(\log \mathrm{S}^{-1}\right)\end{array}$ & $\mathrm{m}_{\mathrm{f}}$ & $\begin{array}{l}\text { fit } \\
(\%)\end{array}$ & $\begin{array}{l}\mathrm{k}_{350^{\circ} \mathrm{C}} \\
10^{-3} \mathrm{~s}^{-1}\end{array}$ \\
\hline 2 & 242 & 18.7 & 0.08 & 0.5 & 27 & 231 & 17.7 & 0.07 & 0.7 & 22 \\
\hline 10 & 238 & 18.3 & 0.05 & 0.5 & 23 & 231 & 17.7 & 0.05 & 0.6 & 22 \\
\hline 77 & 238 & 17.4 & 0.07 & 0.4 & 3 & 231 & 16.8 & 0.06 & 0.5 & 3 \\
\hline 81 & 207 & 15.3 & 0.05 & 0.4 & 10 & 231 & 17.3 & 0.05 & 1.2 & 9 \\
\hline
\end{tabular}

Figure 1a displays both the experimental data and simulated weight loss curves, which were calculated using a first order rate law with the best fit values of $\mathrm{E}$ and $\log \mathrm{A}$ determined at the lowest heating rate. The fit of the first order model to the weight loss data at 2 and $10^{\circ} \mathrm{C} / \mathrm{min}$ in helium is very good. This result is consistent with the hypothesis that the pyrolysis chemistry is governed by a first order rate law with a high activation energy. On the other hand, the fit of the first order model (using the kinetic parameters determined at $2{ }^{\circ} \mathrm{C} / \mathrm{min}$ ) to the higher heating rate data in argon is not good. Nevertheless, the simulated weight loss curve (which employs an activation energy of $242 \mathrm{~kJ} / \mathrm{mol}$ ) is parallel to the experimental curves, suggesting that the experimental curves were shifted along the temperature axis. We interpret these data as follows. In helium at low heating rates with small sample sizes, the temperature measured by the TGA is a good approximation of the sample temperature (i.e. the thermal lag is small). In argon at higher heating rates, the systematic error in temperature measurement becomes important; consequently the temperature reported by the thermocouple is not the true sample temperature. 
Experienced practitioners of thermogravimetry know that thermal lag is influenced by the heating rate, the placement of the thermocouple, the size of the sample, the composition of the carrier gas, the endothermicity of the reaction, etc. For example, the difference in the two high heating rate experimental curves obtained in argon (see Figure 1a) is simply a result of a small change in the position of the thermocouple within the instrument from one year to the next. A similar influence of thermocouple position on sample temperature measurement was observed by Antal et al..$^{5}$ over fifteen years ago. In summary, Figure 1a illustrates the influences of gas composition, heating rate, and thermocouple position on the thermal lag inherent in studies of cellulose pyrolysis by TGA.

Assuming that thermal lag is responsible for the behavior of the curves displayed in Figure 1a, we recognize an uncertainty in our measurement of the sample temperature and we ask how this uncertainty propagates into an uncertainty in a determination of the rate constants. When the thermal lag is almost constant and not too large, the uncertainty in temperature measurement can be represented as an uncertainty in the value of $\log \mathrm{A}$. Figure $1 \mathrm{~b}$ illustrates this concept. In Figure $1 \mathrm{~b}$ the same value of $\mathrm{E}$ is employed in all the simulated weight loss curves, but the value of $\log \mathrm{A}$ is altered by a small amount to account for variations in thermal lag among the weight loss curves. Values of the $\log \mathrm{A}\left(\mathrm{and} \mathrm{m}_{\mathrm{f}}\right.$, the mass fraction of remaining char) used in Figure $1 \mathrm{~b}$ are listed in the "Identical E" section of Table 1. It is evident from Figure $1 \mathrm{~b}$ that a first order model which provides for the intrinsic uncertainty in $\log \mathrm{A}$ (due to thermal lag) realizes a very good fit to all the experimental data. Thus we report a single value of E, and values $\log \mathrm{A} \pm \delta \log \mathrm{A}$, where the $\delta \log \mathrm{A}$ value is the sample standard deviation of the values of $\log$ A employed to fit a data set that includes several weight loss curves. For this example, we write $\log \mathrm{A} / \mathrm{s}^{-1}$ $=17.4 \pm 0.4$, where $\delta \log \mathrm{A}$ is the sample standard deviation of the $\log \mathrm{A}$ values listed in the eighth column of Table 1. In the "Variable E" section of Table 1, values of E and log A are related according to the well-known compensation effect. ${ }^{6}$ To give the reader a feeling for the effects of these variations in $\mathrm{E}$ and $\log \mathrm{A}$, we have listed values of the rate constant at $350{ }^{\circ} \mathrm{C}$ associated with each pair of $\mathrm{E}$ and $\log \mathrm{A}$ values. The range of these calculated values is less than a factor of ten. Finally, we emphasize that we believe the true value of $\mathrm{E}$ for cellulose pyrolysis is close to the value obtained at low heating rates (approximately $240 \mathrm{~kJ} / \mathrm{mol}$ ). We employ lower values (in this case, $231 \mathrm{~kJ} / \mathrm{mol}$ ) in our models only when it is necessary to reconcile the results of low and high heating rate experiments, which are all compromised to a lesser or greater extent by thermal lag. 
Table 2. Response factors of a Hewlett Packard flame ionization detector

\begin{tabular}{lc}
\hline compound & $\begin{array}{c}\text { resp. factor } \\
(\mathrm{g} / \text { area })\end{array}$ \\
\hline methane & $4.1 \times 10^{-13}$ \\
ethene & $4.0 \times 10^{-13}$ \\
ethane & $4.1 \times 10^{-13}$ \\
propane & $3.7 \times 10^{-13}$ \\
methanol & $1.3 \times 10^{-10}$ \\
1-propanol & $1.3 \times 10^{-10}$ \\
\hline
\end{tabular}

Concerning our interpretation of this data, Reynolds and Burnham ${ }^{1}$ remark that “... the $50 \%$ conversion point at $80{ }^{\circ} \mathrm{C} / \mathrm{min}$ would have to be $364{ }^{\circ} \mathrm{C}$, a $30{ }^{\circ} \mathrm{C}$ error!”. We respond that systematic errors this large in thermogravimetry were reported 17 years ago, ${ }^{5}$ and even larger errors can easily be rationalized and anticipated. ${ }^{6}$ Furthermore, one reviewer of this paper commented that "... replacing a furnace in a TGA system resulted in a shift in the weight loss profiles of as much as $30{ }^{\circ} \mathrm{C}$ when cellulose samples were heated at $30{ }^{\circ} \mathrm{C}$ per min., even when a calibration run with calcium oxalate showed no significant difference and runs with a coal sample showed a much smaller difference. This may be due to a higher endothermic reaction heat in the case of cellulose." Like this reviewer, we regularly employ calcium oxalate ${ }^{7}$ and Curie point standards to calibrate our TGA system, but these calibrations vary with sample holder size and heating rate. Moreover, no calibration accounts for thermal lag engendered by the endothermicity of the cellulose pyrolysis reaction! Reynolds and Burnham ${ }^{1}$ also remark that “... it seems highly unlikely that the sample temperature at $80^{\circ} \mathrm{C} / \mathrm{min}$ would be uniform, so that the experiment should be artificially broadened ...”. We reply that this might be the case if we employed large samples in our work, but our emphasis of samples below $1 \mathrm{mg}$ at high heating rates minimizes such temperature nonuniformities. If this were not true, the experimental data displayed in Figure $1 b$ could not be easily fit by a high activation energy model. Finally, Reynolds and Burnham ${ }^{1}$ state that "Várhegyi et al. claim that obtaining good fits to single constant heating rate experiments validates a first-order model and eliminates the need for the serial aspect (activated cellulose) of the Broido-Shafizadeh model." Actually, we claim nothing of the sort! Figure 2 displays all the temperature-time profiles over which weight loss was measured and used to test the validity of the Broido-Shafizadeh model. (This model involves an initiation reaction that forms a hypothetical "activated cellulose" species, followed by competing reactions that consume the "activated cellulose" and produce either volatiles without char, or char with some volatile products.) All the models we examined were required to fit simultaneously all the weight loss data associated with the temperature programs displayed in Figure 2 and recorded in our paper. ${ }^{2}$ We emphasize that these temperature programs included 999 min plateaus at $250,260,275$, and $286{ }^{\circ} \mathrm{C}$, as indicated in Table 1 of that paper, as well as other temperature programs. It is a simple fact that the 
initiation reaction posited by Broido $^{8}$ and Shafizadeh ${ }^{9}$ is not needed to fit weight loss data associated with the temperature programs displayed in Figure 2 (which mimic those used originally by Broido). Furthermore, we remark that Reynolds and Burnham ${ }^{1}$ provide no convincing evidence in support of the Broido-Shafizadeh model. This is in part because they collected no low temperature weight loss data in their work, which are required to evoke the low temperature, char-forming pathway and the hypothetical initiation reaction. Moreover, as discussed in other papers, ${ }^{2,4}$ no one has been able corroborate the Broido-Shafizadeh model since it was first proposed over twenty years ago. While we would welcome such a corroboration, we have only been able to corroborate the model originally proposed by Arseneau, ${ }^{10}$ which lacks the initiation reaction.

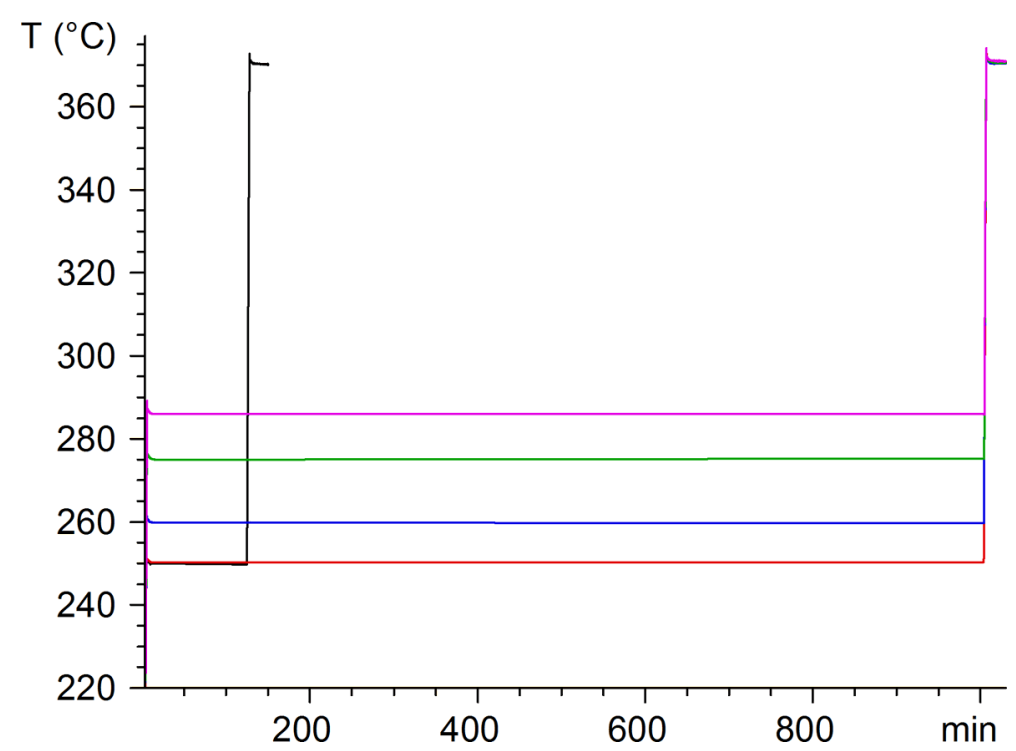

Figure 2. Temperature programs of five experiments which were subject to simultaneous kinetic evaluation and used to check the validity of the Broido-Shafizadeh model. Four experiments included $999 \mathrm{~min}$ isothermal sections at $250^{\circ} \mathrm{C}, \mathbf{2 6 0 ^ { \circ }} \mathrm{C}, 275^{\circ} \mathrm{C}$, and $286^{\circ} \mathrm{C}$, respectively. One experiment was conducted at $250^{\circ} \mathrm{C}$ for $120 \mathrm{~min}$. The heating rate in the non-isothermal sections was $40^{\circ} \mathrm{C} / \mathrm{min}$.

Finally, we observe that attempts to measure cellulose pyrolysis kinetics by other experimental methods are also compromised by systematic errors of one sort or another. For example, the Pyromat micropyrolysis instrument, emphasized by Reynolds and Burnham, ${ }^{1}$ employs a Flame Ionization Detector (FID) to measure volatiles release during pyrolysis. Reynolds and Burnham used this measurement to calculate the kinetics of cellulose weight loss by pyrolysis. Unfortunately, the FID does not detect hydrogen, carbon dioxide, carbon monoxide, water, and char. These pyrolysis products comprise about $30 \%$ of the weight of the original cellulose substrate. In addition to the fact that the FID cannot detect many of the most important products of cellulose pyrolysis, it magnifies the importance of some products relative to others. Table 2 gives response factors for several organic compounds as measured on a Hewlett Packard FID. Clearly the FID signal is proportional to the weight of alkanes evolved during pyrolysis, but it is more than 200 times more sensitive to the evolution of methanol and propanol than the 
alkanes. The products of cellulose pyrolysis include many oxygenates, such as methanol, glycolaldehyde, and levoglucosan, as well as methane and some other hydrocarbons. In light of the facts that the FID ignores the formation of some of the most important products of cellulose pyrolysis, while it exaggerates the formation of others, we believe that more work is needed to prove that the Pyromat instrument provides a reliable measure of the rate of weight loss of a cellulose sample undergoing pyrolysis.

The literature of cellulose pyrolysis well illustrates the vexing problems associated with measurements of the reaction rate of a strongly temperature sensitive substrate, and suggests the need for a round-robin study of cellulose pyrolysis by thermogravimetry. Such a study was initiated about one year ago by the authors, together with other researchers in Europe. We hope to publish the results of this study in early 1998. Thus far a considerable amount of data has been accumulated, which contains no evidence to contradict the material presented in this paper.

\section{Acknowledgment}

This work was funded by the U.S. Hungarian Joint Fund (Grant 93b-375), the Hungarian National Research Fund (Grant T016173) and the Coral Industries Endowment of the University of Hawaii. We thank Professor Angela Garcia for measuring the response factors of our FID and allowing us to include the results in this paper. We also thank Professor John W. Larsen and two anonymous reviewers for their constructive comments.

\section{References}

(1) Reynolds, J.G.; Burnham, A.K. Energy Fuels 1997, 11, 88-97.

(2) Várhegyi, G.; Jakab, E.; Antal, M.J. Energy Fuels 1994, 8, 1345-1352.

(3) Várhegyi, G.; Antal, M.J.; Székely, T.; Szabó, P. Energy Fuels 1989, 3, 329-335.

(4) Antal, M.J.; Várhegyi, G. Ind. Eng. Chem. Res. 1995, 34, 703-717.

(5) Antal, M.J.; Friedman, H.L.; Rogers, F.E. Combust. Sci. Technol. 1980, 21, 141-152.

(6) Narayan, R.; Antal, M.J. Ind. Eng. Chem. Res. 1996, 35, 1711-1721.

(7) Várhegyi, G.; Antal, M.J.; Székely, T.; Till, F.; Jakab, E. Energy Fuels 1988, 2, 267-272.

(8) Broido, A.; In Thermal Uses and Properties of Carbohydrates and Lignins; Shafizadeh, F., Sarkanen, k., Tillman, D.A., Eds.; Academic Press: New York, 1976; pp 19-36.

(9) Bradbury, A.G.W.; Sakai, Y.; Shafizadeh, F.J. J. Appl. Polym. Sci. 1979, 23, 3271-3280.

(10) Arseneau, D.F. Can. J. Chem. 1971, 49, 632-638. 